\title{
Que Direito à Saúde para a População GLBT? Considerando Direitos Humanos, Sexuais e Reprodutivos em Busca da Integralidade e da Eqüidade
}

\section{What Do Health Rights Mean for the GLBT Population? Considering Human, Sexual and Reproductive Rights in the Search for Equity and Integrality in the Health System}

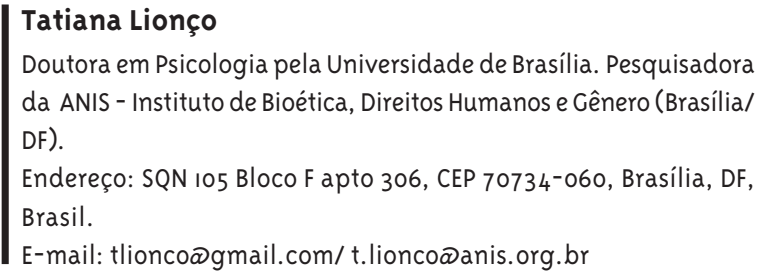

E-mail: tlionco®gmail.com/t.lionco®anis.org.br

\section{Resumo}

Este artigo tem como objetivo problematizar a pertinência de uma política de saúde para a população de Gays, Lésbicas, Bissexuais, Travestis e Transexuais GLBT. A partir da consideração dos processos de violação de seus direitos humanos, sistematicamente comprometidos devido a estigmas e processos discriminatórios, busca-se evidenciar a necessidade de uma política de saúde específica a esta população, na perspectiva da integralidade da atenção e da eqüidade no sistema de saúde. O desafio da construção de uma política de atenção integral à saúde dessa população, tal como prevista no programa de governo federal Brasil sem Homofobia, implica a complexificação e alargamento do que se compreende por direitos sexuais e reprodutivos para a efetiva promoção da eqüidade e universalidade do acesso aos bens e serviços.

Palavras-chave: Direitos sexuais; Direitos reprodutivos; GLBT; Homofobia; Diversidade sexual. 


\section{Abstract}

This paper discusses whether a specific health policy for Gays, Lesbians, Bisexuals, Transvestites and Transsexuals is a good way to improve their lives and health situation, recognizing that their human rights are systematically violated by prejudice and discrimination processes. A health policy could be a strong political and technical instrument for achieving integrality in health care and equity in the health system. Building a health policy according to the constitutional right of universality and integrality in health care is proposed by the Federal Government's program called No Homophobia in Brazil. For its consolidation, we need to broaden what we understand by sexual and reproductive rights.

Keywords: Sexual Rights; Reproductive Rights; GLBT; Homophobia; Sexual Diversity.
A proposição de políticas de saúde para grupos específicos gera polêmica por ser, a princípio, antagônica à universalidade preconizada constitucionalmente aos direitos sociais, dentre os quais o direito à saúde. 0 Sistema Único de Saúde, instituído pela Lei Federal No. 8.080/9o (Brasil, 1990), tem como princípios a universalidade do acesso e a integralidade da atenção. A saúde, enquanto direito de todos e dever do Estado, é, no entanto, um ideal, sendo a realidade brasileira atravessada por iniqüidades que devem ser combatidas com ações que proponham reverter quadros de exclusão e da violação de direitos humanos fundamentais, na perspectiva da promoção da eqüidade para distintos grupos sociais.

Medeiros (1999) discute princípios de justiça nas políticas públicas de saúde, tendo como campo de debate a alocação de recursos. Se, por um lado, a universalidade do direito à saúde como direito de cidadania prevê o princípio da igualdade na proposição de políticas que alcancem a totalidade dos cidadãos, a focalização de ações e políticas específicas é um recurso necessário, muitas vezes, para a própria efetivação da universalidade, mediante promoção da eqüidade entre grupos em situação desigual. A proposição de políticas específicas, no entanto, sobretudo referentes à problemática que não dispõe de um acúmulo reflexivo no próprio âmbito da gestão, encontra como fator dificultador, e mesmo impeditivo, a omissão de destinação orçamentária específica nos Planos PluriAnuais, como é o caso da população de Gays, Lésbicas, Bissexuais, Travestis e Transexuais - GLBT.

Como enfatizado por Campos (2006), a noção de eqüidade não comparece explicitamente como princípio, seja na Constituição Federal seja na legislação relativa ao SUS, mas é afirmado atualmente um conceito-chave para problematizar os entraves que inviabilizam ou retardam o alcance da universalidade e da integralidade, visando superar desigualdades no acesso e no cuidado que, longe do ideal, configuram a realidade do sistema (Costa e Lionço, 2006).

O objetivo deste artigo é sinalizar como fundamento para uma política de saúde para a população GLBT a necessidade da promoção da eqüidade, mediante a reflexão e reconhecimento da condição de vulnerabilidade em que se encontra essa população em relação aos direitos humanos, bem como ao que mais recentemente vem sendo especificado, no campo mais abran- 
gente dos direitos humanos, como direitos sexuais e reprodutivos.

A necessidade de uma política de saúde para essa população já fora evidenciada e formalizada em 2004, quando da elaboração e apresentação, com ampla participação da sociedade civil, do Brasil sem Homofobia - Programa de Combate à Violência e à Discriminação contra GLTB e de Promoção da Cidadania Homossexual - Conselho Nacional de Combate à Discriminação - (Brasil, 2004a). Esse programa do Governo Federal situa no âmago das políticas públicas para a população em questão o combate ao preconceito e às intolerâncias, que têm como conseqüência iniqüidades e falta de garantia de direitos fundamentais a Gays, Lésbicas, Bissexuais, Travestis e Transexuais. Ainda ao que concerne ao setor saúde, instituiu-se em 2004 o Comitê Técnico Saúde da População GLTB no âmbito do Ministério da Saúde, através da Portaria 2.227/GM - D.O.U. 14/11/2004 (Brasil, 2004b). A principal atribuição desse comitê é justamente sistematizar proposta de política nacional da saúde da população GLBT, com vista a garantir a eqüidade na atenção à saúde também para esses segmentos populacionais.

Tomando como parâmetro a perspectiva ampliada da saúde, tal como preconizada como direito de cidadania pela Constituição de 1988, a atenção à saúde da população GLBT não deve ser considerada apenas do ponto de vista da epidemiologia. Sobretudo, diante da escassez dos dados de pesquisas em saúde dessa população, devem ser consideradas as condições e representações sociais associadas à população GLBT, compreendendo que os agravos à saúde desses segmentos populacionais estão, em grande parte, determinados socialmente.

Com isso queremos enfatizar que as necessidades em saúde, bem como os desafios que se colocam para a qualificação da atenção a essa população, dizem respeito não necessariamente a características intrínsecas a gays, lésbicas, bissexuais, travestis e transexuais, mas tão somente às conseqüências das representações e significações que recaem sobre suas práticas sexuais e modos de vida, enquanto desviantes em relação a um suposto padrão de normalidade ou 'saúde' implicado na heteronormatividade moralmente vigente. Esta consideração inicial é importante para explicitarmos que recusamos a associação das práticas sexuais não-heterossexuais, bem como das expres- sões subjetivas relativas à sexualidade, com concepções patologizantes como forma de justificar sua atenção no campo da saúde. Igualmente, gostaríamos de afirmar o estigma e a patologização como determinantes das condições de sofrimento e de agravos à saúde de GLBT.

\section{A População GLBT e a Luta por Direitos Humanos}

O Movimento Social GLBT vem consolidando, no mundo e no Brasil, ampla visibilidade, enfatizando a denúncia da violência e da violação aos direitos humanos desses grupos sociais, e reivindicando a igualdade de direitos. O Brasil vem contribuindo em grande parte para a visibilidade das reivindicações do movimento GLBT, tendo congregado, na Parada do Orgulho GLBT de 2006, em São Paulo, 3 milhões de participantes (Facchini e col., 2007), configurando a maior mobilização social do gênero no mundo. A mobilização da sociedade civil pela reivindicação de direitos igualitários para GLBT vem ascendendo fortemente no Brasil, tendo sido realizadas, em 2005, 75 paradas em diversas localidades do país, passando o número de manifestações, em 2006, para 102 paradas, aumentando para 300 o número de eventos políticos pela visibilidade dessa população em 2007, segundo comunica em rede virtual a Associação Brasileira de Gays, Lésbicas e Transgêneros (ABGLT). Essa ampla mobilização social é conseqüência da crescente organização do movimento GLBT no Brasil, bem como da abertura de espaços governamentais para a discussão de estratégias de enfrentamento dos processos discriminatórios contra grupos sociais que seriam alvo de estigmas e preconceitos excludentes.

o Brasil sem Homofobia - Programa de Combate à Violência e à Discriminação contra GLBT e de Promoção da Cidadania Homossexual (Brasil, 2004a), elaborado a partir das contribuições de lideranças do movimento GLBT, representa uma conquista da sociedade brasileira decorrente de mais de duas décadas de mobilização social. Tal programa se apresenta como proposta intersetorial, abrangendo ações nos setores Saúde, Educação, Cultura, Trabalho e Segurança Pública. Como salienta Ramos (2005), esse programa governamental se estrutura em torno do eixo da violência, enfatizando o combate à discriminação e à homo- 
fobia como estratégias fundamentais para a promoção da cidadania. Para a autora, esta peculiaridade do movimento GLBT ecoa a dinâmica de outros movimentos sociais no Brasil, tais como o movimento negro e o movimento de mulheres, que estabeleceram o racismo, a misoginia e as violências correlatas como motes para a criminalização dessas formas de opressão. A violência e seu combate aparecem como elementoschave potencializadores de outras conquistas de cidadania, que se estruturariam e se legitimariam diante da condição de violência, preconceito e dano, que não se conformariam aos preceitos de universalidade e igualdade preconizados pelos direitos constitucionais.

Para Rios (2007a), a homofobia é correlata ao antisemitismo, ao racismo e ao sexismo, sendo, no entanto, o estado da arte relativo à homofobia, atualmente, notadamente aquém dos demais campos temáticos, que já dispõem de inúmeros estudos que potencialmente podem impulsionar ações de combate às intolerâncias. $\mathrm{O}$ autor propõe redimensionar a noção de homofobia para a idéia de heterossexismo, evidenciando o prejuízo social decorrente da não adequação de pessoas ao padrão heterossexual. Como desafios adicionais para o combate à homofobia, em relação ao anti-semitismo, racismo e sexismo, Rios (2007a) aponta a condenação moral e inaceitabilidade social, muitas vezes sustentada pelo caráter doentio e/ou inferior em relação à heteronormatividade. Ainda, o enfrentamento da homofobia requer a desnaturalização da família como fundada na heterossexualidade, implicando o questionamento do modus vivendi hegemônico.

Ramos (2005) evidencia quatro fatores determinantes do crescimento da visibilidade do movimento GLBT, da década de 1990 até os dias de hoje. Primeiramente, pode-se resgatar a multiplicação de iniciativas, nos campos legislativo, jurídico e da extensão de direitos. É o caso do Projeto de Lei da Câmara No. 122 de 2006, da ex-deputada federal Iara Bernardi, que atualmente tramita no Senado Federal, que prevê a criminalização da homofobia. Vale destacar também a existência de diversas leis municipais já aprovadas, no sentido da criminalização da discriminação por orientação sexual e identidade de gênero, bem como na conquista de benefícios relativos à previdência social.

Importante papel na visibilidade desse movimento também desempenhou a associação da sociabilidade
GLBT a novas possibilidades de mercado e, ainda, como um terceiro importante fator, a adoção, por parte do movimento social, da política de visibilidade massiva, com o surgimento e proliferação das paradas do orgulho. Por fim, cabe ressaltar a indicação de Ramos (2005) da importância da criação de entidades de defesa dos direitos homossexuais e da congregação e convivência entre associações heterogêneas em um movimento comum. Segundo Ramos (2005), no fim da década de 1990, surge uma experiência inédita no Brasil, que propõe uma política pública específica a GLBT no campo da segurança pública. Trata-se da iniciativa do Estado do Rio de Janeiro, por meio da Secretaria de Segurança Pública, da criação do Disque Defesa Homossexual (DDH), com a função de denúncia e defesa dos direitos dos cidadãos, através de articulação entre sistema de polícia e comunidade. Essa iniciativa é de grande relevância, pois, até então, os dados de violência contra GLBT no Brasil eram apenas notificados pela mídia, o que veio sendo sistematizado e divulgado através de dossiês pelo Grupo Gay da Bahia desde a década de 1980.

O DDH, portanto, foi o primeiro canal de visibilidade para a violência contra GLBT que partia da informação da própria vítima, tendo mudado grandemente o teor e as faces da violência. Do sensacionalismo midiático, com ênfase em assassinatos (sem desconsiderar a existência dessas formas de violência), passou-se a reconhecer o caráter amplo e silencioso da homofobia, que emerge como prática discriminatória que atravessa campos cotidianos da vivência de GLBT, como a família, a vizinhança, a escola e o trabalho, partilhando agressor e vítima da mesma rede social, na maior parte das vezes.

O Centro Latino-Americano de Sexualidade e Direitos Humanos - CLAM, vinculado ao Instituto de Medicina Social da UERJ, vem contribuindo com dados relativos à violência contra GLBT por meio de pesquisas realizadas com participantes das paradas do orgulho (em 2003 e 2004 no Rio de Janeiro, e em 2005 em São Paulo). Esses estudos têm a peculiaridade de apresentar questões de vitimização a toda a amostra, alcançando dados relativos à violência que não chegam a ser noticiados pela mídia ou notificados à polícia ou outros órgãos de defesa de direitos.

Segundo Carrara e colaboradores (2003), através 
de pesquisa realizada na $8^{\text {a }}$ Parada do Orgulho GLBT do Rio, em 2003, que contou com 403 participantes, o relato de agressões verbais e ameaças relativas à condição homossexual ou em relação à identidade de gênero recobriu $56,3 \%$ da amostra, revelando que a discriminação homofóbica atinge proporções bastante significativas. Ainda esse estudo revelou que travestis e transexuais são alvos preferenciais de práticas discriminatórias e de violência verbal, somando 65,4\% de ocorrências em relação a $41,5 \%$ das mesmas em gays, lésbicas e bissexuais. Em se tratando de agressões físicas, a proporção de agressões contra travestis e transexuais aumenta para $42,3 \%$, enquanto para lésbicas cai para 9,8\%, 16,6\% para gays e 7,3\% para bissexuais. A pesquisa realizada na $9^{\text {a }}$ Parada do Orgulho GLBT do Rio, em 2004 (Carrara e Ramos, 2005), reitera a alta incidência de discriminação, representando 64,8\% de uma amostra de 629 participantes.

Estudo similar realizado pela Associação da Parada do Orgulho GLBT de São Paulo, em 2006, com uma amostra de 846 participantes, evidencia que $67 \%$ dos respondentes declaram haver sofrido discriminação devido à sua sexualidade, bem como 59\% dos sujeitos já haviam sido vítimas de agressão pelo mesmo fator determinante (Facchini e col., 2007). Ainda que tais estudos não representem a totalidade da população brasileira, representam um importante indicativo da dinâmica de violência que perpassa o cotidiano social de GLBT.

Para Moutinho e Sampaio (2005), um dos maiores problemas reside na ausência de definição da natureza da violência contra a população de homossexuais quando notificada, bem como a subnotificação da mesma. Essa situação não sustenta a continuidade na produção de indicadores que possam auxiliar na definição e na construção de políticas públicas que viessem a reverter o quadro de violência que atinge essa população. Por esse motivo, por mais evidente que seja atualmente a existência de processos discriminatórios e de violência contra GLBT, pode-se supor que a amplitude de seu alcance e sua repercussão é ainda subestimada. 0 direito a não discriminação, bem como o direito à dignidade, são direitos humanos fundamentais, sendo sua violação determinante para a exclusão ou comprometimento do acesso a outros direitos, dentre os quais o direito à saúde.
Recentemente foram propostos os Princípios de Yogyakarta (Corrêa e Muntarbhorn, 2007), efeito da articulação promovida pela Comissão Internacional de Juristas e pelo Serviço Internacional de Direitos Humanos, entre especialistas em direitos humanos de 25 países. O documento propõe a reafirmação dos direitos humanos universais, independentemente de orientação sexual e de identidade de gênero, sinalizando desafios específicos para a promoção dos direitos humanos para GLBT. Aqui, interessam diretamente: o princípio 17, que afirma o direito ao padrão mais alto alcançável de saúde, com especial destaque para o combate às discriminações, ao acesso à assistência sexual e reprodutiva independente de orientação sexual e de identidade de gênero, e o reconhecimento de parceiros e parceiras como parentes mais próximos em configurações familiares não-heterossexuais; e o princípio 18, que afirma a proteção contra abusos médicos, no qual se destaca a recomendação de que nenhum tratamento médico ou psicológico deva visar a cura ou a eliminação de determinada orientação sexual e/ou identidade de gênero.

Faz-se necessário não apenas reconhecer que os processos discriminatórios e de violência contra GLBT decorrem em agravos à sua saúde, tais como sofrimento psíquico, vulnerabilidade ao uso abusivo de álcool, cigarro e outras drogas (Rede Feminista de Saúde, 2006); que o preconceito de profissionais sobre as práticas sexuais e sociais de GLBT acarreta na desqualificação da atenção dispensada a essa população, como já explicitado na literatura acadêmica no caso das mulheres lésbicas e bissexuais (Rede Feminista de Saúde, 2006; Pinto, 2004); que as conseqüências dos processos discriminatórios alcançam, portanto, o próprio sistema de saúde (Carrara e Ramos, 2005).

Faz-se necessário, fundamentalmente, reafirmar a universalidade dos direitos humanos, dentre os quais o direito à saúde, resgatando GLBT como sujeitos de direitos, já que os processos de estigma e discriminação vêm comprometendo o seu exercício da cidadania. Caso resguardados os princípios ético-políticos do SUS em sua efetiva consolidação, o sistema de saúde brasileiro pode ser uma ferramenta política e social privilegiada para o combate à homofobia e demais estratégias correlatas de violação dos direitos humanos fundamentais. 


\section{Por uma Nova Perspectiva dos Direitos Sexuais e Reprodutivos}

Como observa Vianna e Lacerda (2004), a trajetória dos Direitos Humanos parte da afirmação da liberdade individual, primando pela definição de direitos universais soberanos em relação às circunstâncias estatais, e avança na direção da responsabilização dos estados na garantia de direitos que passam a ser depurados e especificados segundo a particularidade dos indivíduos e grupos sociais. A discussão sobre os direitos humanos apresenta, portanto, um movimento pendular que explicita o antagonismo que o caracteri$\mathrm{za}$, ao afirmar sincronicamente o direito à igualdade $\mathrm{e}$ à diferença, à universalidade e à especificidade.

Nesse movimento de especificação dos direitos universais em ressalvas a grupos específicos, emerge a consideração da situação das mulheres, adentrando o tema da sexualidade a partir deste recorte nas pautas das convenções das Nações Unidas. Para Vianna e Lacerda (2004), a conferência realizada no Cairo, em 1994, representa um marco para a reflexão de direitos sexuais, sendo resultado do amadurecimento das discussões acadêmicas feministas. Nessa conferência, além de questões relativas ao combate à violência sexual, bem como à saúde reprodutiva das mulheres, emerge a idéia de direitos sexuais, que representaria o alargamento da consideração da sexualidade para além do viés da lógica da reprodução sexuada, abrangendo também as dimensões de bem-estar e prazer dos indivíduos. No ano seguinte, em 1995, realiza-se em Pequim a IV Conferência Mundial sobre a Mulher, consolidando a relação entre direito e sexualidade.

Corrêa (2006) tece uma análise crítica sobre o processo de consolidação da associação do direito à sexualidade, tendo sido os direitos sexuais, nas conferências das Nações Unidas que trataram do tema, restritos à consideração da condição das mulheres, excluindo do debate os demais atores que têm seus direitos humanos violados em função da sexualidade, tais como GLBT e profissionais do sexo.

Essa crítica é de especial interesse já que reflete a dinâmica dos debates nacionais sobre direitos sexuais e reprodutivos. A priorização da mulher como sujeito dos direitos sexuais e reprodutivos está explicitada na Carta do Rio de Janeiro (Leal, 2007) -
Pelos direitos sexuais ereprodutivos, pela eqüidade de gênero e em defesa do Estado laico, produzida por pesquisadores, docentes, estudantes, gestores e profissionais, participantes do Seminário Saúde, Direitos Sexuais e Reprodutivos: subsídios para as políticas públicas, realizado no Rio de Janeiro, em 24 de agosto de 2007. Vale também notar que o padrão heterossexual está pressuposto na Política Nacional de Atenção Integral em Reprodução Humana Assistida, do Ministério da Saúde (Portaria No. 426/GM, D.O.U. 23/ 03/2005) (Brasil, 2005), restringindo, dessa forma, os sujeitos beneficiários das práticas assistidas de reprodução.

Para Rios (2007b), fundamental é que o debate avance segundo a direção apontada pelas ciências sociais, ao desassociar a sexualidade necessariamente da noção de reprodução, bem como problematizando a noção de 'saúde sexual', abrindo o campo para a consideração de diferentes expressões e possibilidades do exercício da sexualidade para além da naturalização da heterossexualidade.

Rios (2007b) propõe a formulação de um direito democrático da sexualidade, enfatizando a necessidade da discussão sobre direito e sexualidade a partir da perspectiva da universalidade dos direitos humanos. Para o autor, três grandes eixos têm estruturado o debate atual sobre direitos sexuais: (1) a questão das identidades, relativas às expressões da sexualidade, onde se insere notadamente a questão das homossexualidades e das identidades de gênero; (2) as conseqüências e condições da relação sexual, referentes, sobretudo, às práticas de prevenção ou planejamento da concepção, bem como às abortivas; e (3) a busca pela fundamentação dos direitos sexuais, que estaria historicamente referida à noção de 'saúde sexual'.

Em texto sobre 'Direitos Sexuais de Gays, Lésbicas e Transgêneros no Contexto Latino-Americano', Rios (2007C) sugere que, apesar de o Brasil apresentar alto grau de proteção institucional, desde a edição do II Plano Nacional de Direitos Humanos e do Programa Brasil sem Homofobia, ao menos formalmente, bem como da existência de legislações municipais que criminalizem a discriminação por orientação sexual,

a pesquisa mais panorâmica da situação dos direitos GLBT na região (Latino-américa) revela, ainda, a ausência de uma regulamentação fundada na 
perspectiva dos direitos humanos quando se cuida da situação específica da transexualidade ou de travestis. Nestas frentes, aliás, costumam prevalecer abordagens biomédicas, especialmente no que respeita à transexualidade. Quanto ao tratamento dirigido a travestis, mesmo nos países onde tal condição não é considerada ilícita, predomina uma abordagem repressiva, a partir da criminalização de atos considerados obscenos na via pública e da repressão à prostituição (Rios, 2007c, p. 5).

Um fator importante no desencadeamento da consideração de direitos sexuais na região latino-americana, segundo Rios (2007c), foi a resposta à epidemia de HIV/Aids que, ainda que de início tenha associado travestis e homossexuais a grupos de risco, incitando a estigmatização a esses grupos sociais, avançou em suas estratégias de enfrentamento para a consciência dos efeitos discriminatórios bem como a da relação necessária entre a questão da sexualidade e a do Direito. Nessa perspectiva, Rios $(2007 \mathrm{C})$ afirma que 0 desenvolvimento dos direitos GLBT avançou e se consolidou na consideração de questões relativas ao acesso aos serviços de saúde. Trata-se de uma peculiaridade da experiência latino-americana no processo de construção de direitos sexuais que contemplem a população GLBT, e que diferencia a lógica jurídica da região em relação aos processos análogos na América do Norte e na Europa.

Enquanto no Brasil e em outros países da América Latina a questão dos direitos sexuais e da população GLBT avança a partir de demandas por direitos sociais (acesso a bens e serviços estatais, tais como previdência, saúde), nos EUA e Europa esses direitos avançaram desde demandas que invocam o direito à privacidade e a não sofrer discriminação, ou seja, dos direitos negativos ou os da não intromissão do Estado e de terceiros nas escolhas individuais. Um dos desafios para o avanço dos direitos sexuais no Brasil e na América Latina, segundo sugere Rios $(2007 \mathrm{C})$, é a tendência para a justificação biomédica desses direitos, o que nos lança novamente à problemática associação entre direitos sexuais e a idéia de 'saúde sexual'. Segundo o autor (idem), o discurso médico contribui em grande parte para a patologização de identidades e práticas sexuais socialmente estigmatizadas, alimen- tando e legitimando processos discriminatórios. Diante dessa afirmação, cabe esclarecer que a luta por um direito democrático da sexualidade requer a desmedicalização do discurso e das práticas a respeito dos direitos sexuais e reprodutivos, democratizando a discussão sobre sexualidade para além do viés médicobiológico.

Cabe salientar que desvincular a discussão da sexualidade da dimensão reprodutiva não implica na desconsideração da pertinência da questão dos direitos reprodutivos para GLBT. Para Ventura (2005), a introdução das noções de direitos sexuais e reprodutivos na Conferência do Cairo, realizada em 1994, foi um importante marco, mas insuficiente por não abordar problemas que envolvem a Bioética e o Direito, tais como o acesso, a utilização e o desenvolvimento de novas tecnologias para a reprodução humana, acompanhadas por normas legais relativas às configurações familiares e às possibilidades de filiação decorrentes dessas novas tecnologias.

A demanda por reprodução assistida vigora não apenas entre casais homossexuais (gays e lésbicas), mas também entre travestis e transexuais, indicando um complexo campo de reflexão para o Direito. Souza (2007) enfatiza a existência do desejo pela maternidade em casais de mulheres lésbicas, que recorrem às novas tecnologias reprodutivas, artifício este que permite prescindir das relações sexuais heterossexuais como condição da procriação. Vale ressaltar que há casais que lançam mão da 'inseminação caseira' como medida que propõe superar as dificuldades encontradas para a reprodução humana assistida, no caso de não comporem o núcleo heterossexual pressuposto na regulamentação de tais processos. Sardá (2007) problematiza ainda mais a necessidade de redimensionar a configuração familiar segundo um modelo plural, e não mais único, diante das potencialidades abertas pelas novas tecnologias reprodutivas para os direitos sexuais e reprodutivos de GLBT, com especial destaque para transexuais, demandando uma revisão das próprias definições de paternidade/maternidade diante dos paradoxos instaurados pela dicotomia entre a condição biológica e a da identidade de gênero, sobretudo quando se reconhece legalmente a condição do sexo de acordo com a identidade subjetiva. 
Pela Eqüidade e Integralidade na Saúde da População GLBT: considerando avanços $e$ sinalizando desafios

Fundamental ao avanço da consolidação do direito à saúde integral para GLBT é o enfrentamento das condições em que seus direitos humanos são violados ou negligenciados. 0 direito à saúde integral para essa população requer o redimensionamento dos direitos sexuais e reprodutivos, demandando a desnaturalização da sexualidade e de suas formas de manifestação, bem como a recusa à medicalização da sexualidade, que tende a normatizar as expressões da sexualidade humana segundo a lógica heteronormativa e da linearidade na determinação do sexo sobre o gênero. Isso implica considerar outros discursos sobre a sexualidade humana como legítimos, inclusive como ferramenta crítica ao saber/poder médico que tende a patologizar e medicalizar as diferenças que denunciam a não naturalidade, no humano, dos processos constitutivos e das práticas sociais e relacionais vinculadas à sexualidade.

Atentar às possibilidades plurais de constituições humanas em termos psíquicos e relacionais, resguardando aos sujeitos humanos o direito à autonomia, ao livre desenvolvimento da personalidade, à privacidade e à dignidade, implica conceber a homossexualidade como uma possibilidade humana legítima, assim como a heterossexualidade, e não como desvio de um padrão de normalidade. 0 reconhecimento de que a reprodução da espécie deixa de ser o motivo e o fundamento da relação sexual, concebida finalmente como prática humana imersa na lógica do prazer e da cultura, é fundamental para que se possam democratizar os direitos sexuais e reprodutivos. Ainda, implica em reconhecer a possibilidade de constituições humanas que não atestem a linearidade da determinação do sexo biológico sobre os destinos da subjetivação, tais como evidenciam mulheres e homens transexuais, pela incongruência entre a identidade de gênero e o sexo anatômico, e as travestis, pela ostentação da marca da duplicidade dos sexos em suas constituições identitárias.

No Brasil, a retirada da categoria homossexualismo dos compêndios nosográficos, bem como a clareza de outros campos do saber quanto ao caráter não patoló- gico das práticas homoeróticas, acarretou em normatizações específicas por parte de órgãos reguladores de categorias de classe da área da saúde. O Conselho Federal de Psicologia (1999), através da Resolução No 001/99, estabelece normas de atuação para psicólogos em relação à questão da orientação sexual, enfatizando que devem contribuir com seu conhecimento para reflexões críticas sobre os preconceitos e primar pelo combate à discriminação e estigma contra aqueles que apresentam comportamentos ou práticas homoeróticas, não devendo esses profissionais exercer quaisquer ações que favoreçam a patologização dessas pessoas, sequer adotando ações coercitivas que tendam a orientar homossexuais a tratamentos não solicitados. Aos psicólogos está vetado, a partir dessa resolução, tratamento e cura das homossexualidades.

O Conselho Federal de Serviço Social (2006), por sua vez, através da Resolução №. 489/20o6, estabelece normas vetando condutas discriminatórias ou preconceituosas, por orientação e expressão sexual por pessoas do mesmo sexo, no exercício profissional do assistente social, resguardando ao sujeito o direito à singularidade e à diferença subjetiva. Infelizmente os conselhos de classe profissionais se omitem em relação à necessidade de despatologização dos modos de ser transexuais e travestis, restando a esses indivíduos a nosologia médico-psiquiátrica como referencial norteador do exercício profissional não apenas de médicos, mas também com reverberações sobre a atuação de psicólogos e outros profissionais do campo da saúde.

A garantia do direito à saúde para a população GLBT, superando a violação de seus direitos humanos rumo à promoção da eqüidade no sistema de saúde, requer, necessariamente, que se avance na perspectiva da democratização dos direitos humanos, mediante o reconhecimento das diversas possibilidades de constituição humanas e do exercício da sexualidade. Nesta perspectiva, o SUS, por meio da Carta dos Direitos dos Usuários da Saúde (Portaria No 675/GM, D.O.U 31/o3/2006) (Brasil, 2006), deu um passo à frente ao assegurar o atendimento humanizado e livre de preconceito e discriminação por orientação sexual e identidade de gênero, inclusive assegurando o uso do nome social para travestis e transexuais como estratégia de promoção de acesso ao sistema.

Ainda se requer a democratização dos direitos se- 
xuais e reprodutivos, rompendo com a naturalização vigente na estrita associação desses direitos aos direitos das mulheres, mediante explícito questionamento da naturalização da configuração familiar heterossexual. Cabe mencionar que a principal ferramenta de acesso ao sistema de saúde, na Atenção Básica, consiste na estratégia de Saúde da Família, demandando ampla conscientização, por parte dos agentes comunitários de saúde, das diferentes modalidades de constituição de redes familiares distintas do padrão heterossexual.

Os direitos à privacidade, à autonomia e ao livre desenvolvimento da personalidade devem ser preservados, através de amplo reconhecimento da diversidade das possibilidades eróticas e subjetivas, primando pelo respeito à singularidade dos sujeitos e combatendo todas as formas de normatização que impliquem em processos de exclusão e de discriminação das pessoas. A universalidade do direito à saúde requer que se proponham estratégias de acolhimento e atenção específicas, de acordo com as particularidades dos sujeitos que buscam os serviços de saúde. Implica a compreensão de que a orientação sexual e a identidade de gênero são determinantes que estão articulados a outros condicionantes, tais como classe social, idade, cor e etnia. Implica também incluir discussões sobre orientação sexual e identidade de gênero nos currículos de formação dos profissionais da saúde, bem como atualização mediante processos de educação permanentes. Há de se avançar na problematização da naturalização das relações sexuais e das manifestações das sexualidades e subjetividades para que a construção do SUS efetivamente viabilize, para a população GLBT, seus direitos de cidadania concernentes ao campo da saúde integral.

A necessidade da consolidação de uma cultura democrática pelo direito à saúde integral, envolvendo a complexificação e o alargamento da compreensão dos direitos sexuais e reprodutivos, requer que a discussão sobre saúde para esses segmentos populacionais se construa em estreita interface com o campo jurídico. Como exemplo dos desafios concretos que se colocam para além da superação do estigma e da homofobia, vale mencionar a consideração da orientação sexual e identidade de gênero em normas e políticas para as práticas assistidas de reprodução. Também se destaca a necessidade da regulamentação da atenção a travestis na perspectiva da redução de danos pelo uso indiscriminado de hormônios e da aplicação do silicone líquido industrial, demandando a proposição de normas que permitam ao profissional não ter suas práticas interventivas significadas legalmente como crimes de lesão corporal. Cabe ainda notar a necessidade do questionamento crítico do desejo pela cirurgia transgenital ser tomado como critério diagnóstico para a transexualidade, lembrando que o Projeto de Lei 6.655, de 2006, do ex-deputado Luciano Zica, aprovado na Câmara dos Deputados e atualmente tramitando no Senado como PLC 72/2007, prevê alteração no registro civil de transexuais mediante o diagnóstico, não tendo necessariamente como condição viabilizadora da alteração do assentamento jurídico a realização ou desejo pela cirurgia de transgenitalização.

Esses desafios, contudo, só podem ser enfrentados caso a gestão rompa com processos de discriminação institucionalizados. A orientação sexual e identidade e gênero já são fatores incluídos em variadas políticas e ações estratégicas em saúde, dentre as quais a Política de Atenção Integral à Saúde do Jovem e Adolescente, a Política de Atenção Integral à Saúde da Mulher, a Política Nacional de Humanização, a Política de Promoção da Eqüidade na Saúde da População Negra, bem como nos Planos de Enfrentamento à Epidemia de HIV/Aids entre Gays, HSH e Travestis e o de Feminização da Epidemia, e o projeto Saúde e Prevenção nas Escolas, para citar algumas. Isso reflete que a orientação sexual e a identidade de gênero, mais do que demandar uma política específica, devem ser pauta para diversas políticas enquanto determinantes associados a outros determinantes na saúde das pessoas.

Orientação sexual e identidade de gênero, no entanto, acabam por, na maior parte das vezes, figurar como conceitos sem definição, e, conseqüentemente, sem a indicação de encaminhamentos pertinentes à especificação da realidade de vida e saúde da população GLBT. É nesse sentido que uma política específica se faz necessária: para informar e formar conhecimento quanto a estratégias necessárias de ação em saúde, diante da especificidade das vivências de GLBT, qualificando ações e provocando transversalmente diversas áreas técnicas, objetivando a integralidade e a eqüidade. 


\section{Referências}

BRASIL. Ministério da Saúde. Lei Federal no 8.o8o, de 19 de setembro de 1990. Brasília, DF, 1990.

BRASIL. Conselho Nacional de Combate à

Discriminação. Brasil sem homofobia: programa de combate à violência e à discriminação contra GLTB e promoção da cidadania homossexual. Brasília, DF:

Ministério da Saúde, 2004a.

BRASIL. Ministério da Saúde. Portaria No 2.227/GM, de 14 de outubro de 2004. Dispõe sobre a criação do Comitê Técnico para a formulação de proposta da política nacional de saúde da população de gays, lésbicas, transgêneros e bissexuais - GLTB. Diário Oficial da União, Brasília, DF, 14 out. 2004b. Seção II, p. 24.

BRASIL. Ministério da Saúde. Portaria No 426/GM, de 22 de março de 2005. Institui, no âmbito do SUS, a Política Nacional de Atenção Integral em Reprodução Humana Assistida e dá outras providências. Diário Oficial da União, Brasília, DF, 22 mar. 2005. Seção I, p. 22.

BRASIL. Ministério da Saúde. Portaria N 675/GM, de 30 de março de 2006. Aprova Carta dos Direitos dos Usuários da Saúde, que consolida os direitos e deveres do exercício da cidadania na saúde em todo o país. Diário Oficial da União, Brasília, DF, 31 mar. 2006. Seção I, p. 131.

CAMPOS, G. W. de S. Reflexões temáticas sobre equidade e saúde: o caso do SUS. Saúde e Sociedade, São Paulo, v. 15, n. 2, p. 23-33, 2006.

CARRARA, S.; RAMOS, S. Política, direitos, violência e homossexualidade: $9^{\text {a }}$ Parada do Orgulho GLBT -

Rio 2004. Rio de Janeiro: CEPESC, 2005.

CARRARA, S.; RAMOS, S.; CAETANO, M. Política, direitos, violência e homossexualidade: $8^{\mathrm{a}}$ Parada do Orgulho GLBT - Rio 2003. Rio de Janeiro: Pallas, 2003.

CONSELHO FEDERAL DE PSICOLOGIA. Resolução ${ }^{0}$ 01/1999, de 22 de março de 1999. Estabelece normas de atuação para os psicólogos em relação à questão da orientação sexual. Disponível em: <http:// www.crpo7.org.br/upload/legislacao/ legislaca039.pdf >. Acesso em: 17 jun. 2007.
CONSELHO FEDERAL DE SERVIÇO SOCIAL.

Resolução nº 489/2006, de 3 de junho de 2006.

Estabelece normas vedando condutas

discriminatórias ou preconceituosas, por orientação

e expressão sexual por pessoas do mesmo sexo, no

exercício profissional do assistente social, regulamentando princípio inscrito no Código de Ética Profissional. Disponível em: <http:// www.rits.org.br/rets/download/ campanhas110707.pdf>. Acesso em: 12 set. 2007. CORRÊA, S. Cruzando a Linha Vermelha: questões não resolvidas no debate sobre direitos sexuais, Horizontes Antropológicos, Porto Alegre, ano 12, n. 26, p. 101-121, 2006.

CORRÊA, S. O. E MUNTARBHORN, V. (orgs.). Princípios de Yogyakarta: princípios sobre a aplicação da legislação internacional de direitos humanos em relação à orientação sexual e identidade de gênero. Disponível em: <http://www.clam.org.br/ pdf/principios_de_yogyakarta.pdf $>$. Acesso em: 12 set. 2007.

COSTA, A. M.; LIONÇO, T. Democracia e gestão participativa: uma estratégia para a eqüidade em saúde? Saúde e Sociedade, São Paulo, v. 15, n 2, p. 47$55,2006$.

FACCHINI, R.; FRANÇA, I. L.; VENTURI, G. Sexualidade, cidadania e homofobia: pesquisa da $10^{a}$ Parada do Orgulho GLBT de São Paulo. São Paulo: APOGLBT, 2007.

LEAL, A. F. (org.) Carta do Rio de Janeiro: pelos direitos sexuais e reprodutivos, pela equidade de gênero e em defesa do Estado laico. Rio de Janeiro: [s.n], 2007. Disponível em: <http:// www.petitiononline.com/cartario/petition.html>. Acesso em: 2 set. 2007 .

MEDEIROS, M. Princípios de justiça na alocação de recursos em saúde. Rio de Janeiro: IPEA, 1999. (Texto para Discussão, 687).

MOUTINHO, L.; SAMPAIO, C. A. M. Sexualidade, violência e justiça: mapeamento, localização e diagnóstico das pesquisas sobre violência sexual e de gênero no Brasil. In: MOUTINHO, L.; CARRARA, S.; AGUIÃO, S. (Org.). Sexualidade e comportamento sexual no Brasil: dados e pesquisas. Rio de Janeiro: UERJ. CEPESC, 2005. p. 11-37. 
PINTO, V. M. Aspectos epidemiológicos das doenças sexualmente transmissiveis em mulheres que fazem sexo com mulheres. 2004. Dissertação (Mestrado em Epidemiologia) - Faculdade de Saúde Pública da Universidade de São Paulo, São Paulo, 2004.

RAMOS, S. Violência e homossexualidade no Brasil: as políticas públicas e o movimento homossexual. In: GROSSI, M. P. et al. (Org.). Movimentos sociais, educação e sexualidades. Rio de Janeiro: Garamond, 2005. p. 31-44.

REDE FEMINISTA DE SAÚDE. Saúde das mulheres lésbicas: promoção da equidade e da integralidade. Porto Alegre, 2006.

RIOS, R. R. O conceito de homofobia na perspectiva dos direitos humanos e no contexto dos estudos sobre preconceito de discriminação. In: RIOS, R. R. (Org.). Em defesa dos direitos sexuais. Porto Alegre: Livraria do Advogado, 2007a. p. 111-139.

RIOS, R. R. Notas para o desenvolvimento de um direito democrático da sexualidade. In: RIOS, R. R. (Org.). Em defesa dos direitos sexuais. Porto Alegre: Livraria do Advogado, 2007b. p. 13-38.
RIOS, R. R. Direitos sexuais de gays, lésbicas e transgêneros no contexto latino-americano. Disponível em: <http://www.clam.org.br/pdf/ rogerport.pdf $>$. Acesso em: 12 jan. 2007. 2007C

SOUZA, E. R. Maternidade lésbica e novas tecnologias reprodutivas. In: FERREIRA, V.; ÁVILA, M. B.; PORTELLA, A. P. (Org.). Feminismo e novas tecnologias reprodutivas. Recife: SOS Corpo, 2007. p. 135-162.

SARDÁ, A. Lesbiandad, maternidad y nuevas tecnologias reproductivas. In: FERREIRA, V.; ÁVILA, M. B.; PORTELLA, A. P. (Org.). Feminismo e novas tecnologias reprodutivas. Recife: SOS Corpo, 2007. p. 119-134.

VENTURA, M. Direitos reprodutivos?: de que direitos estamos falando? In: LOYOLA, M. A. (Org.). Bioética, reprodução e gênero na sociedade contemporânea. Rio de Janeiro: ABEP; Brasília, DF: Letras Livres, 2005. p. 115-138.

VIANNA, A.; LACERDA, V. Direitos e políticas sexuais no Brasil: mapeamento e diagnóstico. Rio de Janeiro: CEPESC, 2004. 